\title{
Determinants of Infertility Among Couples Seeking Treatment in A Selected Clinic in Dhaka City
}

\author{
Mossamat Afroza Chowdhury \\ Md Monoarul Haque ${ }^{2^{*}}$ \\ Shahanaz Chowdhury ${ }^{3}$ \\ Md Shafiullah Prodhania ${ }^{4}$
}

'Department of Gynae and Obstetrics Bangabandhu Sheikh Mujib Medical University (BSMMU) Dhaka, Bangladesh.

${ }^{2}$ Department of Community Nutrition Faculty of Public Health

Bangladesh University of Health Sciences (BUHS) Dhaka, Bangladesh.

${ }^{3}$ Department of Community Medicine Bangladesh University of Health Sciences (BUHS) Dhaka, Bangladesh.

${ }^{4}$ Consultant \& Chairman

DPRC Hospital

Dhaka, Bangladesh.

\section{${ }^{*}$ Correspondence to:}

\section{Md Monoarul Haque}

Fellow

Dept of Community Nutrition, Faculty of Public Health, Bangladesh University of Health Sciences (BUHS) 125/1, Darus Salam, Mirpur, Dhaka-1216, Bangladesh. Mobile: +88 01915839550

E-mail: monoarmunna@yahoo.com

\begin{abstract}
Background: Infertility is a global health issue affecting approximately $8-10 \%$ of couples and has multidimensional problem with social, economic and cultural implications, which can take threatening proportions in countries with strong demographic problems. Objective: To investigate the determinants of infertility among couples seeking treatment. Methodology: A cross sectional study was conducted in selected private clinic of Dhaka city among 196 infertile couple by face to face interview using pretested semi structured questionnaire. Results: The sample studied consisted of 196 infertile couple. One third (38\%) aged 26-30 years, majority Muslims (96\%), housewives (72\%) and one fourth (24\%) had education level of secondary to higher secondary. Slightly more than half of their family income was taka 5361-21270. More than three fourth (66\%) had primary infertility. Concerning the determinants of infertility polycystic ovary, hormonal imbalance, and fallopian tube blockage was $19 \%, 16 \%$ and $7 \%$ respectively but unexplained factors $(28 \%)$ crossed the other factors. Only male factor was $10 \%$ and combined male and female factors were $10 \%$ among study subjects. Regarding the daily habits of the male participants, $18 \%$ were smokers. Conclusions: The determinants of female infertility are problems in the fallopian tubes and the uterus, disorders of menstruation, sexual disorders, age and ovarian failure. Female infertility is a complex problem that should be considered carefully by the government and stakeholders in each country in order to find effective interventions and solutions.
\end{abstract}

Key words: Infertility; Hormonal imbalance; Sexual disorders.

\section{INTRODUCTION}

WHO defines infertility as failure to conceive despite two years of cohabitation and exposure to pregnancy. If the couple has never conceived despite cohabitation and exposure to pregnancy for a period of two years, it is called primary infertility, primary infertility is also referred to as primary infertility. If a couple fails to conceive following a previous pregnancy, despite cohabitation and exposure to pregnancy (in the absence of contraception, breastfeeding or postpartum amenorrhea) for a period of two years, it is secondary infertility; this is also known as secondary infertility ${ }^{1}$. It has been established that primary infertility is more common than secondary infertility in resource-rich countries but that the reverse is true in resource-poor countries. Infertility is a global health issue, affecting approximately $8-10 \%$ of couples worldwide. It is a multidimensional problem with social, economic and cultural influences. A global review of infertility from the World Fertility Survey and other estimated similar rates of infertility in other settings in South Asia, such as 4\% in Bangladesh, 6\% in Nepal, 5\% in Pakistan and 4\% in Sri Lanka $^{2}$. Ninety percent of a woman's eggs degrade at the end of her 37 th year, by the time she decides to have a baby, her 'biological clock' often slows down. She then requires the help of an ART (assisted reproductive technique) specialist to conceive. 
Although the infertility problems are increasing with time, the medical science has also increased the chances of giving solution to the problem by Assisted Reproduction ${ }^{3}$. There is greater awareness of the problem and also availability of more effective treatments like In-vitro Fertilization even in countries like Bangladesh. The average age of childbearing has increased over the past three decades as more women have pursued and careers and postponed marriages ${ }^{4}$. The determinants of infertility include, endocrine dysfunction which is a significant cause and leads to ovulatory infertility. For example, thyroid dysfuntion, hyperandrogenism, polycystic ovarian disease. Sexually transmitted diseases like gonorrhea and chlamydial infection may cause tubal infertility. Congenital anomalies of uterus and autoimmune disease have impact on conception and pregnancy loss. (pathophysiological determinants of human infertility) Furthermore, other indirect causal factors of infertility are worth mentioning here, like anaemia, malnutrition, poverty and tuberculosis. The potential risk factors of infertility are widely present in Bangladesh. According to Bangladesh Fertility Society, the causes of such a situation of infertility were menstrual regulation, delayed marriage and environmental pollution ${ }^{3}$. Studies show that in our sub-continent, reproductive health problems like sexually transmitted diseases (STD), urinary tract infections (UTI), reproductive tract infections (RTI), unhygienic delivery, post partum infection and unsafe obstetric and abortion procedures are linked to sepsis and pelvic infections, which can cause infertility ${ }^{5}$. Like many other health problems, certain type of infertility is preventable. As women age, the risk of infertility rises because of diminished egg quality and ovulatory function as well as in increase in disorders such as endometrioisis, leiomyomata and tubal disease ${ }^{6}$. Infertility among women of reproductive age is an emerging problem in Bangladesh. The effects of infertility for couples who are unable to conceive can be devastating in a society like ours and can cause psychological stress, anxiety and depression. This study therefore, aims to assess the risk factors of infertility among women of reproductive age and create awareness about the infertility problems.

\section{MATERIALS \& METHODS}

A cross sectional study was conducted among 196 couples $(n=392)$ selected purposively who were seeking help for their infertility problem in a private infertility care center named Bangladesh Infertility Management Center (BIMC). This center was selected purposively for data collection. The study subjects were included couples that came with infertility problem, and has been trying for at least 6 months to conceive and couples who can show all the medical reports of their investigation and treatment and who were willing to participate and provide required information. Before data collection, permission had taken from the Head of the Infertility Management Center (BIMC). All the study subjects were informed about the study. After collection, data were checked thoroughly for consistency and completeness. All analysis was done by appropriate statistical methods using Statistical package for Social Sciences (SPSS) software for Windows version 11.5.

\section{RESULT}

Table 1 shows that age range of female respondents were 20-25 years $20 \%, 26-30$ years $38 \%, 31-35$ years $23 \%, 36-40$ years $15 \%$ and $41-45$ years only $4 \%$. The minimum age groups of female respondents were 20 and maximum age groups of female were 45 with mean age 30.36 and standard deviation 5.752. It also shows that majority $96 \%$ respondent were Muslim and rest 4\% were Hindu. Among all the respondents 54\% were lower middle income group (5361-21270), 38\% were upper middle income group (21270-65761) and only 8\% were low income group according to 2006 Gross National Income (GNI) per capita and using the calculation of World Bank. Most of the female respondents $(72 \%)$ were housewife followed by service $(15 \%)$, business $(4 \%)$, and teacher $(7 \%)$ and most of the female respondents had secondary to graduate level of education. The table also shows that male participants were doing business and service. Regarding overweight, normal and obese female were $45 \%, 41 \%$ and $13 \%$ respectively.

Table 2 shows that overweight; normal and obese female was $45 \%, 41 \%$ and $13 \%$ respectively.

Figure 1 In figure 1 it is shows that primary infertility was quite double $(66 \%)$ than secondary infertility $(34 \%)$.

Figure 2 shows that polycystic ovary, hormonal imbalance, tube blockage was $19 \%, 16 \%, 7 \%$ respectively but unexplained factors $(28 \%)$ crossed the others. Only male factor was $10 \%$ and combined male and female factors were $10 \%$ among study subjects.

Table 3 shows that $78 \%$ of male had no habit only $18 \%$ smoked Figure 3 pie chart shows that $80 \%$ male had normal semen and $19 \%$ were suffering from oligospermia and azospermia was only $1 \%$.

Table 1: Distribution of female respondents by age $(n=196)$

\begin{tabular}{|c|c|c|}
\hline Age of female respondents & Frequency & Percentage \\
\hline $20-25$ & 39 & 20 \\
\hline $26-30$ & 75 & 38 \\
\hline $31-35$ & 45 & 23 \\
\hline $36-40$ & 30 & 15 \\
\hline $41-45$ & 7 & 4 \\
\hline Mean & $30.36 \pm 5.752$ & \\
\hline \multicolumn{3}{|l|}{ Religion } \\
\hline Muslim & 188 & 96 \\
\hline Hindu & 8 & 4 \\
\hline \multicolumn{3}{|l|}{ Monthly family income } \\
\hline$<5360$ & 15 & 8 \\
\hline $5361-21270$ & 106 & 54 \\
\hline $21271-65761$ & 75 & 38 \\
\hline$>65761$ & 0 & 0 \\
\hline \multicolumn{3}{|l|}{ Occupation of wife } \\
\hline Housewife & 142 & 72 \\
\hline Service & 29 & 15 \\
\hline Business & 7 & 4 \\
\hline Teacher & 11 & 7 \\
\hline Others & 7 & 4 \\
\hline \multicolumn{3}{|l|}{ Education } \\
\hline Illiterate & 4 & 2 \\
\hline Primary & 18 & 9 \\
\hline Secondary & 46 & 24 \\
\hline Higher-secondary & 46 & 24 \\
\hline Graduation or more & 82 & 41 \\
\hline \multicolumn{3}{|l|}{ Occupation of husband } \\
\hline Business & 86 & 44 \\
\hline Service & 89 & 45 \\
\hline Others & 21 & 11 \\
\hline Total & 196 & 100 \\
\hline
\end{tabular}


Table 2 : Distribution of female respondents by BMI $(n=196)$

\begin{tabular}{lcr} 
BMI & Frequency & Percentage \\
Underweight & 1 & 1 \\
Normal & 81 & 41 \\
Overweight & 89 & 45 \\
Obese & 25 & 13 \\
Total & 196 & 100 \\
\hline
\end{tabular}

Table1 3 : Distribution of male respondents by habit $(\mathrm{n}=196)$

\begin{tabular}{lcr} 
Habit of husband & Frequency & Percentage \\
No habit & 154 & 78 \\
Smoking & 36 & 18 \\
Alcohol & 3 & 2 \\
Others & 3 & 2 \\
Total & 196 & 100 \\
\hline
\end{tabular}

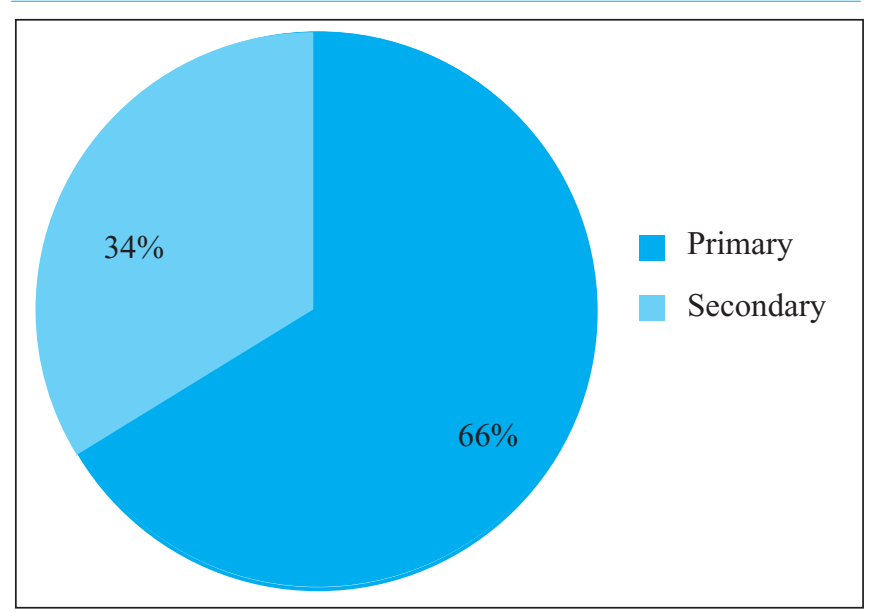

Figure 1: Types of infertility ( $\mathrm{n}=196)$
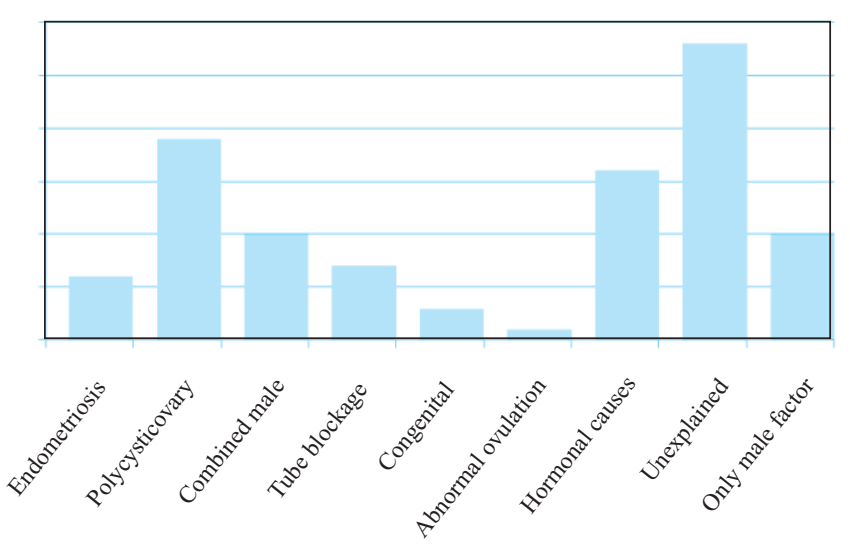

Figure 2 : Distribution of determinants of infertility among respondents $(\mathrm{n}=196)$

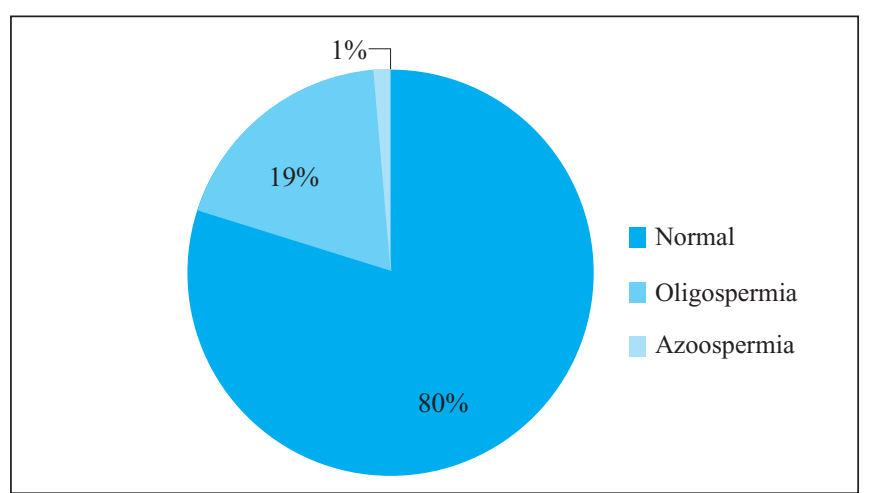

Figure 3 : Distribution of infertility due to male factors on the basis of semen analysis $(n=196)$

\section{DISCUSSION}

Of $\mathrm{t}$ A cross sectional study was done in a private infertility care center named Bangladesh Infertility Management Center (BIMC) situated in Dhanmondi, Dhaka. It is well-known among people, and it is run by highly qualified and skilled doctors. Number of clients per day is around 40-50. Middle to high-class people can afford their treatment in this place. This place is well-equipped and provides good patient- compliance. Table 1 shows that age range of female respondents were 20-25 years $20 \%$, 26-30 years 38\%, 31-35 years 23\%, 36-40 years $15 \%$ and $41-45$ years only $4 \%$. The minimum age groups of female respondents were 20 and maximum age groups of female were 45 with mean age 30.36 and standard deviation 5.752. One study in Pakistan showed that a strong association exists between sub fertility and increasing female age ${ }^{7}$. The reduction in fertility is greatest in women in their late 30 s and early 40 s which is similar with this study. A classic report on the effect of female age on fertility found that the percentage of women not using contraception that remained childless rose steadily according to their age at marriage: $6 \%$ at age 20 to 24 , $9 \%$ at age 25 to $29,15 \%$ at age 30 to $34,30 \%$ at age 35 to 39 and $64 \%$ at age 40 to $44^{8}$. Similarly, a sharp decline in pregnancy rate with advancing female age is noted with donor insemination studies (which control for fertility of the male partner and coital frequency) and with assisted technologies including in vitro fertilization'. The risk of spontaneous abortion increases with female age ${ }^{10}$. It also shows that majority 96\% respondent were Muslim and rest $4 \%$ were Hindu. According to the religion $96 \%$ respondent were Muslim and rest $4 \%$ were Hindu. Religion is seen to play a role in the desire for children, in the aetiology of infertility, in negotiating infertility and in attitudes to assisted conception technologies ${ }^{11}$. Table 2 shows that overweight, normal and obese female was $45 \%, 41 \%$ and $13 \%$ respectively. Lifestyle factors that influence fertility include weight problems and smoking. The American Society for Reproductive Medicine reports that $12 \%$ of infertility cases are the result of women weighing either too much or too little ${ }^{12}$. Maintaining a healthy weight can help increase the chances of getting pregnant. 
Figure 1 In figure 1 it is shows that primary infertility was quite double (66\%) than secondary infertility (34\%). Another study was done in Mongolia showed that $43.7 \%$ of women had secondary infertility ${ }^{13}$.

Figure 2 shows that in case of determinants of infertility this study found that polycystic ovary, hormonal imbalance, tube blockage was $19 \%, 16 \%, 7 \%$ respectively but unexplained factors $(28 \%)$ crossed others. In Mongolian study found that $32.8 \%$ of women had a tubal factor ${ }^{13}$. Only male factor was $10 \%$ and combined male and female factors were $10 \%$ among this study subjects. In $45.8 \%$ of couples, infertility was due to a female factor and in $25.6 \%$ of cases, infertility was due to a male factor. $9.8 \%$ of couples had no demonstrable cause in either partner and $18.8 \%$ of couples had an infertility diagnosis in both partners ${ }^{13}$.

While smoking is one of the main causes of infertility and most of the population in Greece is aware that has many negative consequences, about half of the female population smokes regularly, and only $20 \%$ of these consider to quit smoking ${ }^{14-18}$. But this study in table 3 found that $78 \%$ male had no habit and only $18 \%$ smoked.
Figure 3 pie chart shows that $80 \%$ male had normal semen and $19 \%$ were suffering from oligospermia and azospermia was only $1 \%$. In Mongolian study found that $45.8 \%$ of couples, infertility was due to a female factor and in $25.6 \%$ of cases; infertility was due to a male factor. $9.8 \%$ of couples had no demonstrable cause in either partner and $18.8 \%$ of couples had an infertility diagnosis in both partners ${ }^{13}$.

\section{CONCLUSION}

Childbearing and family are considered a right of every human being. Infertility is a health problem that requires appropriate diagnosis and determinants. The main determinants of female infertility were polycystic ovary, endometriosis, hormonal imbalance, fallopian tube blockage, congenital malformation and other unknown causes. The study concluded that though the female respondents were more evaluated than male; the number of female factors contributing in infertility was found to be quite large.

\section{DISCLOSURE}

All the authors declared no competing interest.

\section{REFERENCES}

1. Czerwinski BS, Wardell DW, Yoder LH, Connely LM, Ternus M, Pitts K, et al. Variation in feminine hygiene practices of military female in deployed and non-combatan environments. Mil Med. 2001; 166: 153-158.

2. Kumar D et al., Prevalence of female infertility and its socio-economic factors in Tribal communities of Central India; Rural and Remote Health. 2007;7:456.

3. Roupa Z. et al., causes of infertility in women at reproductive age: Health Science Journal. 2009;3.

4. The CDC, American Society for Reproductive Medicine, and Society for Assisted Reproductive Technology. 2001 assisted reproductive technology success rates. Atlanta, GA: US Department of Health and Human Services, CDC, 2003.

5. Nahar P. Invisible women in Bangladesh: Stakeholders' views on infertility services (Monograph). 2012; 30-37.

6. Baird DT, Collins J, Egozcue J, et al. Fertility and ageing. Hum Reprod Update. 2005; 11:261-276.

7. Hakim A, Sultan M, Uddin F. Pakistan reproductive health and family planning survey : preliminary report Islamabad: National Institute of Population Studies. 2001; 30.

8. Menken J, Trussell J, Larsen U. Age and Infertility. Science.1986;233:1389-1394.

9. Schwartz D, Mayaux MJ. Female fecundity as a function of age: results of artificial insemination in 2193 nulliparous women with azoospermic husbands. N Engl J Med.1982; 306: 404-406.

10. Smith KE, Buyalos RP. The profound impact of patient age on pregnancy outcome after early detection of fetal cardiac activity. Fertil Steril.1996; 65:35-40.

11. Religion, Infertility and Infertility Treatment ; Culley, Lorraine ; Hudson, Nicky ; Norton, Wendy https://www.dora.dmu.ac.uk/handle/2086/8892.

12. American Society for Reproductive Medicine. (2012). Quick facts about infertility. Retrieved June 11, 2012, from http://www.asrm.org/detail.aspx?id=2322.

13. Bayasgalan et al. Clinical patterns and major causes of infertility in Mongolia. J. Obstet. Gynaecol. Res. 2004; 30(5):386-393.

14. Hart R. Unexplained infertility, endometriosis and fibroids. BMJ.2003;327(7417):721-724.

15. Sépaniak S., Forges T., Monnier-Barbarino P. Cigarette smoking and fertility in women and men. Gynecol Obstet Fertil. 2006;34(10):945-949.

16. Practice Committee of the American Society for Reproductive Medicine. Smoking and infertility. Fertil Steril. 2006;86(5 Suppl):S172-177.

17. Berthiller J., Sasco AJ. Smoking (active or passive) in relation to fertility, medically assisted procreation and pregnancy. J Gynecol Obstet Biol Reprod. 2005;34 (1) :3S47-54.

18. de Mouzon J., Belaisch-Allart J. Consequences on women's fecundity and on assisted reproductive technology. J Gynecol Obstet Biol Reprod (Paris). 2005 ;34 (1) :3S112-118. 